
NBSIR $75-770$

\section{THE EQUATION OF STATE FOR AMMONIA}

Lester Haar

John Gallagher

Equation of State Section

Heat Division

Institute for Basic Standards

National Bureau of Standards

Washington, D. C. 20234

Interim Report

September 1975

This is an interim report. The final report will appear in the Journal of Physical and Chemical Reference Data.

This report is to be superseded by a future publication which will receive general distribution and should be cited as a reference. Please consult the NBS Office of Technical Information and Publications to obtain the proper citation.

Prepared for

The Office of Standard Reference Data

National Bureau of Standards

Washington, D C. 20234

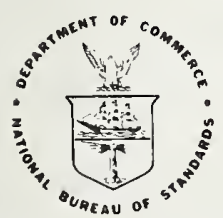

U.S. DEPARTMENT OF COMMERCE, Rogers C.B. Morton, Secretary James A. Baker, III, Under Secretary Dr. Betsy Ancker-Johnson, Assistant Secretary for Science and Technology

NATIONAL BUREAU OF STANDARDS, Ernest Ambler, Acting Director 

The Equation of State for Ammonia

by

Lester Haar and John Gallagher

\section{Introduction.}

In this report, we present an outline of the basic results of an extensive correlation of the thermodynamic properties of ammonia 1 . The purpose of this report is to present an early working version of that correlation for the convenience of those workers with an immediate need for such results and to which they can refer in an unambiguous manner. This report has been prepared in answer to several urgent requests for such a version.

We present the basic equations used for the description of the properties of ammonia and listings of computer programs from which all the thermodynamic properties for ammonia can be calculated for the temperature range including the triple point temperature to about 5/3 the critical temperature and for the pressure range including the dilute gas to about 8000 bars. The reference state for all properties is the ideal gas at zero kelvin. The physical constants used are consistent with those recommended by Cohen and Taylor ${ }^{2}$. The mass of a mole of ammonia was taken to be $17.03026 \mathrm{grams}^{3}$. 2. The derivation of the thermodynamic surface.

In this section, we describe the results of a fit of selected $\mathrm{P}, \rho, \mathrm{T}$ data schematically represented in figure 1 to an analytic equation of state in the least squares sense. A detailed discussion of the process of data selection and of the selection of parts of the analytic equation is contained in reference 1 . The equation so obtained contains the pressure as a 44 term double power series function of temperature and density. This equation can then be used to 
reproduce all the available $\mathrm{P}, \rho, \mathrm{T}$ experimental data as well as to produce limited extrapolations (based on thermodynamic arguments) of the surface into important regions where data are sparse. The range of the equation is bounded at low temperatures by the triple point temperature (195.48K) and the melting curve for the liquid, and at high temperatures by the isotherm at $750 \mathrm{~K}$ (which is approximately $5 / 3$ the critical temperature). The pressure range extends to 8,000 bar. No mathematical constraints were imposed on the equation, and only $P, \rho, T$ data were used in the least squares fit.

Foliowing fieenan et al. the hielmloltz free energy function was represented in reference 1 as the sum of two terms: the first is the contribution from the equation of state; the second is a function of temperature only and refers to the properties of the ideal gas. Thus the Helmholtz free energy was expressed,

$$
A(p, T)=\bar{A}(p, T)+A^{0}(T),
$$

where $A^{\circ}(T)$ is the contribution of the ideal gas. $T$ is the absolute temperature in Kelvin and $\rho$ is the density in grams per $\mathrm{cm}^{3}$. A quantity $O(\rho, T)$ was defined by

$$
\bar{A}(\rho, T) \equiv R T[\ln \rho+\rho Q(\rho, T)]
$$

Since $\quad P=\rho^{2} \partial A / d \rho$,

Eq8. (1) and (2) yleld,

$$
P=\rho R T\left[1+\rho Q+\rho^{2} \partial Q / \partial \rho\right] .
$$


We note that

$$
Q(p=0)=B_{2},
$$

where $B_{2}$ is the second virial coefficient. The form chosen for $Q$ was

$$
Q=\sum_{1=1}^{9} \sum_{j=1}^{6} a_{1 j} \rho^{1-1}\left(\tau-\tau_{c}\right)^{j-1}
$$

where $\tau=\frac{500}{\mathrm{~T}}, \tau_{\mathrm{c}}=1.2333498$ and $\mathrm{R}$ is the gas constant. Equation 3 for the pressure was fitted in the least squares sense to the experimental $\mathrm{P}, \rho, \mathrm{T}$ data. The results of this fit are values for the constants $a_{i j} 1$ isted in table 1.

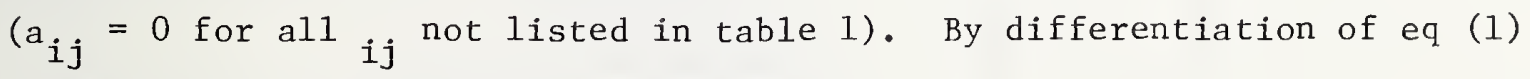
we obtain for the entropy,

$$
S(\rho, T)=R[\ln \rho+\rho Q-\rho \tau \partial Q / \partial \tau]+S^{\circ}(T), .
$$

the internal energy,

$$
E(p, T)=\mathbb{R} P T \partial Q / \partial \tau+E^{\circ}(T)
$$

the constant volume heat capacity,

$$
C_{v}(\rho, T)=-R D \tau^{2} \partial^{2} Q / \partial \tau^{2}+C_{v}^{0},
$$


Table 1

1

1

1

1

1

1

1 j

1 2 3 4 5 6 1 2 3 4 5 6 1 2 3 $a_{11}$

$-6.4690439557$

$-13.295625875$

$-8.1211770915$

$-6.9690043553$

$-9.7365802349$

3. 4816642617

8.8100445762

$-5.0789548707$

$-68.261583422$

$-74.727156949$

49.751854179

$-14.487156374$

$-10.467902857$

361.91907645

1327.8270222

1484.2843304

$-82.229122939$

20.170856719

75.049574001

$-2103.9451938$

$-7576.1007937$

$-8334.8746422$

43.998475959

$-9.2773376718$

$-409.02964153$

6212.2822515

22341.800329

23618.791735

1072.479955

$-10816.10642$

$-38259.344112$

$-38233.534003$

$-1471.4013145$

11195.138723

38544.628190

35887.294649

1046.2341301

$-6365.7466698$

$-21314.815310$

$-18162.094974$

$-305.80081169$

1532.0616045

5021.6962092

3812 . 3691534 
the enthalpy function,

$$
H(\rho, T)=R T\left[\rho Q+\rho^{2} \partial Q / \partial \rho+\rho \tau \partial Q / \partial \tau+1\right]+E^{0}(T),
$$

the constant pressure heat capacity,

$$
C_{p}(\rho, T)=C_{v}+R \cdot \frac{\alpha}{\bar{B}},
$$

where,

$$
a=1+\rho Q+\rho^{2} \partial Q / \partial \rho-\rho \tau \partial Q / \partial \tau-\rho^{2} \tau \partial^{2} Q / \partial \tau \partial \rho,
$$

and

$$
B=1+2 \rho Q+4 \rho^{2} \partial Q / \partial \rho+\rho \partial^{2} Q / \partial \rho^{2},
$$

the heat capacity for the saturated fluid,

$$
C_{S}=C_{P}-\frac{T}{\rho^{2}} \frac{(\partial P / \partial T)_{\rho}}{(\partial P / \partial \rho)_{T}} \cdot \frac{d P}{d T},
$$

where $P_{S}$ is the vapor pressure of the liquid.

$S^{0}, E^{0}$ and $C_{v}{ }^{\circ}$ are the corresponding contributions obtained from $A^{\circ}(T)$ :

$$
\begin{aligned}
& A^{0}(T)=\left(G^{\circ}-E_{0}^{0}\right)-R T(1+\ln 4.8180 T), \\
& S^{0}=-\frac{d}{d T} A^{\circ}(T), \\
& E^{0}=A^{\circ}(T)-T \frac{d A^{\circ}(T),}{d T}, \\
& C_{V}^{0}=-T d^{2} A^{0}(T) / d T^{2},
\end{aligned}
$$


where $G^{\circ}$ is an analytic representation of the results reported by Haar ${ }^{5}$ for the properties of the ideal gas state,

$$
\frac{G^{\circ}-E_{O}^{\circ}}{R T}=a_{1} \ln T+\sum_{i=2}^{11} a_{i} T^{i-3} \text {, }
$$

where $\mathrm{E}_{0}^{\circ}$ is the energy for the ideal gas at $0 \mathrm{~K}$. The coefficients $\mathrm{a}_{i}$ are listed in table 2 .

Table 2

$$
\begin{aligned}
& a_{1}=-3.872727 \\
& a_{2}=.64463724 \\
& a_{3}=3.2238759 \\
& a_{4}=-.0021376925 \\
& a_{5}=.86890833 \times 10^{-5} \\
& a_{6}=-.24085149 \times 10^{-7} \\
& a_{7}=.36893175 \times 10^{-10} \\
& a_{8}=-.35034664 \times 10^{-13} \\
& a_{9}=.2056303 \times 10^{-16} \\
& a_{10}=.6853420 \times 10^{-20} \\
& a_{11}=.9939243 \times 10^{-24}
\end{aligned}
$$

The heat capacity values and the other thermodynamic functions calculated from eq (10a) for the temperature range $100 \mathrm{~K} \leq \mathrm{T} \leq 1000 \mathrm{~K}$ agree with those tabulated in reference 5 to within the accuracy of those values. 
Though equations ( $1-10 a)$ are complete, it is necessary to introduce the Gibbs phase conditions in order to calculate the properties for the coexisting phases. However, it was shown by Haar and Gallagher ${ }^{1}$, that almost negligible error results if an explicit relation is used for $\mathrm{P}_{9}$ fitted separately to the saturated vapor pressure data of Cragoe $^{6}$ for the range from the triple point to $373 \mathrm{~K}$ and of the mean of the data of Beattie and Lawrence ${ }^{7}$ and Keyes $^{8}$ above $373 \mathrm{~K}$. The equation so obtained is

$$
\begin{aligned}
\log _{e} P_{S} & =\frac{A}{T}+B+C T+D T^{2}+E T^{3} \\
& T \text { in kelvin (IPTS68), } P \text { in atm. } \\
=A & =-3684.7798 \\
= & =20.428787 \\
= & C=-.02893289 \\
= & D=3.4798128 \times 10^{-5} \\
=E & =-9.2219845 \times 10^{-9}
\end{aligned}
$$

Equation (10b) and eq (3) define the coexisting phases for this report and al1 properties over the temperature-pressure range of the thermodynamic surface, subject to the low temperature boundary of the melting solid. The thermodynamic surface is consistant with the following values for the parameters at the triple point,

$$
\begin{aligned}
& \mathrm{T}_{\mathrm{t}}=195.48 \mathrm{~K} \\
& \mathrm{P}_{\mathrm{t}}=.06063 \mathrm{bar} \\
& \rho_{\mathrm{t}}^{\mathrm{g}}=.00006382 \mathrm{~g} / \mathrm{c}^{3}, \rho_{t}^{\ell}=.73374 \mathrm{~g} / \mathrm{c}^{3},
\end{aligned}
$$

and at the critical point,

$$
\begin{aligned}
& \mathrm{T}_{\mathrm{c}}=405.4 \mathrm{~K} \\
& \mathrm{P}_{\mathrm{c}}=113.04 \mathrm{bar} \\
& \rho_{c}=.2350 \mathrm{~g} / \mathrm{c}^{3}
\end{aligned}
$$


The relationship between the pressure and temperature of the melting solid was calculated by means of the Clapyron equation, using the latent heat of fusion and the specific volumes for the saturated liquid and solid. For the latent heat, the value reported by Overstreet and Giauque ${ }^{9}$ was used; for the specific volume for the solid at the normal melting point, the value reported by McKelvey and Taylor ${ }^{10}$ was used, and for the corresponding specific 
volume of the liquid the value reported by Cragoe and Harper ${ }^{11}$ was used. The Clapeyron equation is the relation

$$
\frac{\mathrm{dT}}{\mathrm{T}}=\frac{\mathrm{u}^{\prime}-\mathrm{u}}{\mathrm{L}} \mathrm{dP}
$$

where the quantities $u^{\prime}$ and $u$ refer to the specific volumes of the liquid and solid, respectively, and $L$ refers to the latent heat of fusion. From the above data, the quantity $\frac{\mathrm{u}^{\prime}-\mathrm{u}}{\mathrm{L}} \cong 4 \times 10^{-5} \mathrm{~atm}^{-1}$; and $\mathrm{Eq}$ (11) can be integrated to yield

$$
T=T_{S} \exp \left[4 \times 10^{-5}\left(P-P_{S}\right)\right]
$$

where $\mathrm{T}_{\mathrm{S}}$ and $\mathrm{P}_{\mathrm{S}}$ are the triple point values. (The differences between the triple point values and those of the normal melting point are negligible.) Also, since $\mathrm{P}_{\mathrm{S}}$ at the triple point is very small, the relationship can be simplified to

$$
T=195.48 \exp \left\{4 \times 10^{-5} \mathrm{P}(\mathrm{atm})\right\}
$$

\section{Computer programs.}

The properties calculated from the equations presented in this report have been compared with the various thermodynamic measurements reported for ammonia in the comprehensive review in reference 1 . In almost all cases the agreement is within the experimental accuracy of the data. Comparisons of results with $P, \rho, T$ data are given here in figures 2 and 3 . It was established in reference 1 that for most of the vapor phase and for the coexisting phases, the calculated enthalpies are accurate to within $0.1 \%$. 
To facilitate the application of these results we present in Appendices I and II computer programs with which the various properties of ammonia can be calculated. Two such programs are included:

Computer program I in Appendix I refers only to certain properties for the coexisting phases, including the latent heat of vaporization, the vapor pressure of the saturated liquid, the densities of the saturated vapor and the saturated 1iquid. The dependent variable for these is either the temperature or the corresponding pressure of the saturated liquid.

Computer program II in Appendix II is a general program for al1 the thermodynamic properties discussed in section 2 of this report. The dependent variables are either pressure and temperature or density and temperature. 
1. L. Haar and J. Gallagher, Thermodynamic Properties for Ammonia,

Submitted for publication in the Jnurnal of Physical and Chemical Reference Data.

2. E. R. Cohen and B. N. Taylor, Fundamental Physical Constants, J. Phys. Chem. Ref. Data 2, No. 4, 663 (1973).

3. A. E. Cameron and E. Wickers, Report on the International Committee on Atomic Weights (1961). J. Am. Chem. Soc. 84, 4192 (1962).

4. J. F. Keenan, F. G. Keyes, P. G. Hill, and J. G. Moore, Steam Tables, John Wiley and Sons, New York (1969).

5. L. Haar, Thermodynamic Properties of Ammonia as an Ideal Gas, J. Research N.B.S. 72A, 207 (1968).

6. C.S. Cragoe, C.H. Meyers and C.S. Taylor, Vapor Pressure of Ammonia, Sci. Pap. Bur. Stand. 16, 1 (1920).

7. J.A. Beattie and C.K. Lawrence, Some of the Thermodynamic Properties of Ammonia, I. The Compressibility and an Equation of State for Ammonia, J. Am. Chem. Soc. 52, 6 (1930).

8. F.G. Keyes and D.B. Brownlee, The Vapor Pressure of Liquid Ammonia up to the Critical Temperature. J. Am. Chem. Soc. 40, 25 (1918).

9. R. Overstreet and W.F. Giauque, Ammonia, The Heat Capacity and Vapor Pressure of Solid and Liquid, Heat of Vaporization, The Entropy Values from Thermal and Spectral Data, J. Am. Chem. Soc. 59, 254, (1937).

10. E.C. McKelvey and C.S. Taylor, Composition, Purification, and Certain Constants of Ammonia. Sci. Pap. Bur. Stands. 18, 655 (1923).

11. C.S. Cragoe and D.R. Harper, 3d, Specific Volume of Liquid Ammonia, Sci. Pap. Bur. Stands. 17, 287 (1921).

12. C.H. Meyers and R.S. Jessup, The Specific Volume of Superheated Ammonia Vapor, Refrig. 11, 345 (1925). 
13. C.S. Cragoe, E.C. McKelvey, and G.F. O'Connor, Specific Volume of Saturated Ammonia Vapor, Sci. Pap. Bur. Stands. 18, 655 (1923).

14. J.S. Kazarnowsky, The Compressibility of Ammonia at High Temperatures and High Pressures, Acta. Phys. Chim. U.S.S.R. 12, 513 (1940).

15. F.G. Keyes, The Pressure-Volume-Temperature Values for Ammonia to One Thousand Atmospheres, J. Am. Chem. Soc. 53, 965 (1931).

16. K. Date, Studies on the P-V-T Relations of Fluids at High Pressures, I. The Compressibility of Ammonia, Rev. of Phys. Chem. of Jap. 43, 1 (1973).

17. A. Kumagai and T. Toriumi, Pressure-Volume-Temperature Relationship of Liquid Ammonia, J. of Chem. and Eng. Data 16, 293 (1971).

18. D.S. Tsiklis, Compressibility of Ammonia Under Pressures to 10,000 Atmospheres, Acad. of Sci. U.S.S.R. 91, 889 (1953).

19. A. Harlow and E.U. Frank, Private Communication from E.U. Frank.

20. K. Date, Studies of PVT Relations of Fluids at High Pressures, II. Relations for Ammonia in the Neighborhood of the Critical Point and The Critical Values for Ammonia, Rev. of Phys. Chem. Japan 43, 17 (1973). 


\section{Figure Caption}

Fig. 1. P-T Schematic of the data included in this correlation. The various polygons represent the range of the individual sets. The numbers refer to references in this report for the sources of the various data sets.

Figs. 2,3. Comparisons of calculated values with $\mathrm{P}, 0, \mathrm{~T}$ data. The results are presented as fractional differences in percent vs pressure in atmospheres. The numbers to the left of the various plots refer to data references in the text. Figure 2 refers to pressure deviations for densities less than 1.5 times the critical density. Figure 3 refers to density deviations for values of density greater than 1.5 times the critical density. 



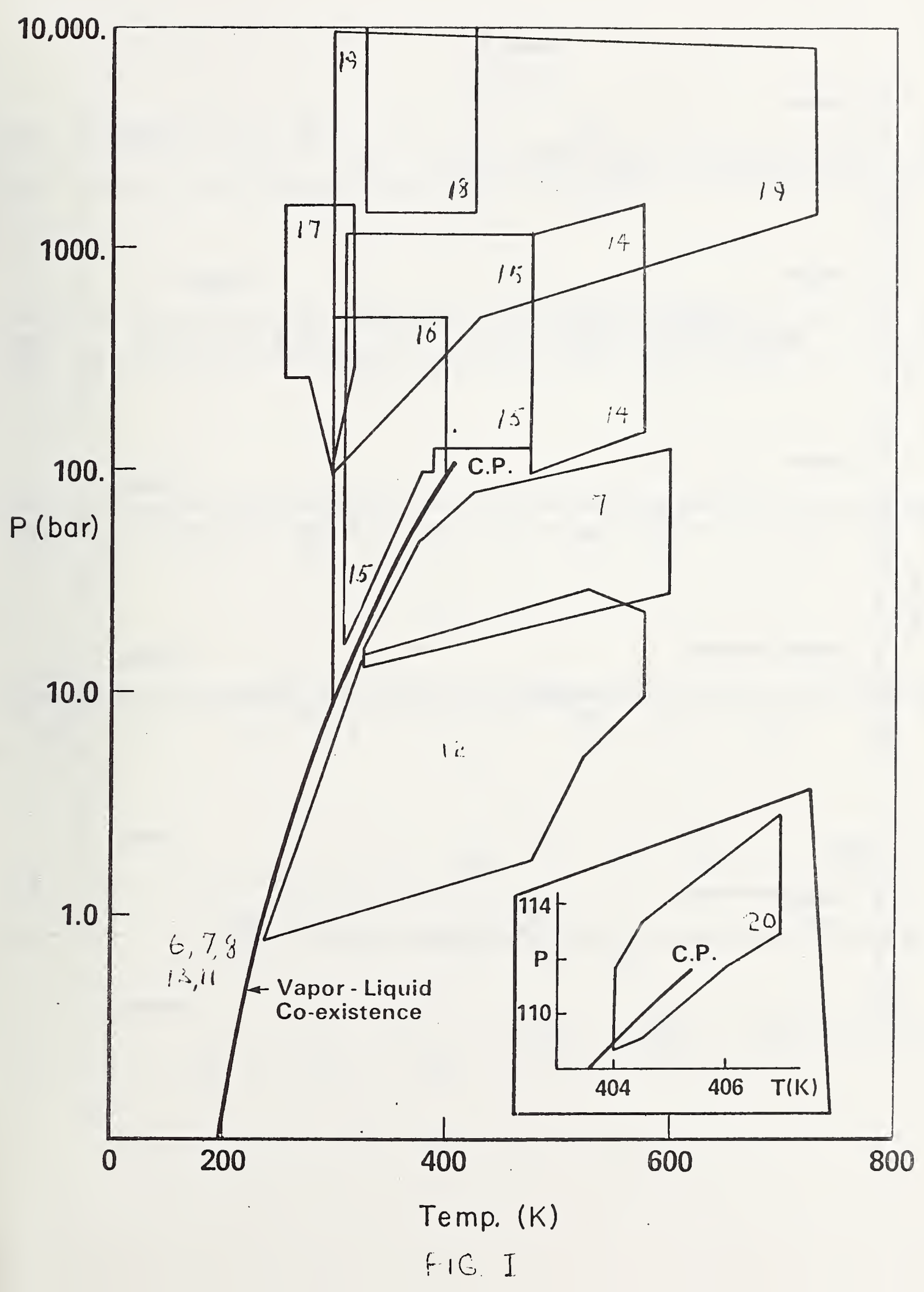


Figure 2

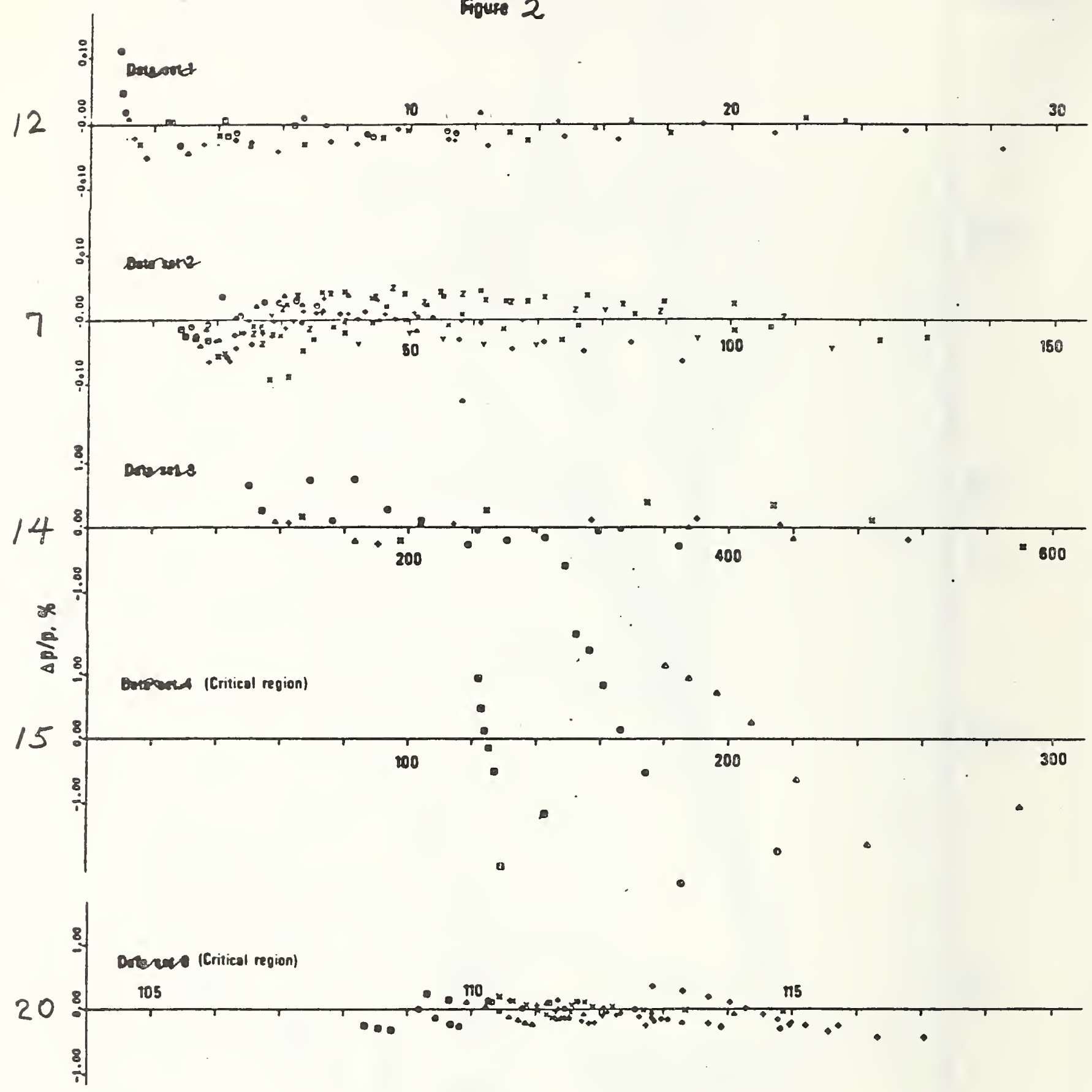


Figure 3

porrea

14

$-1$

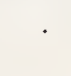

afraca

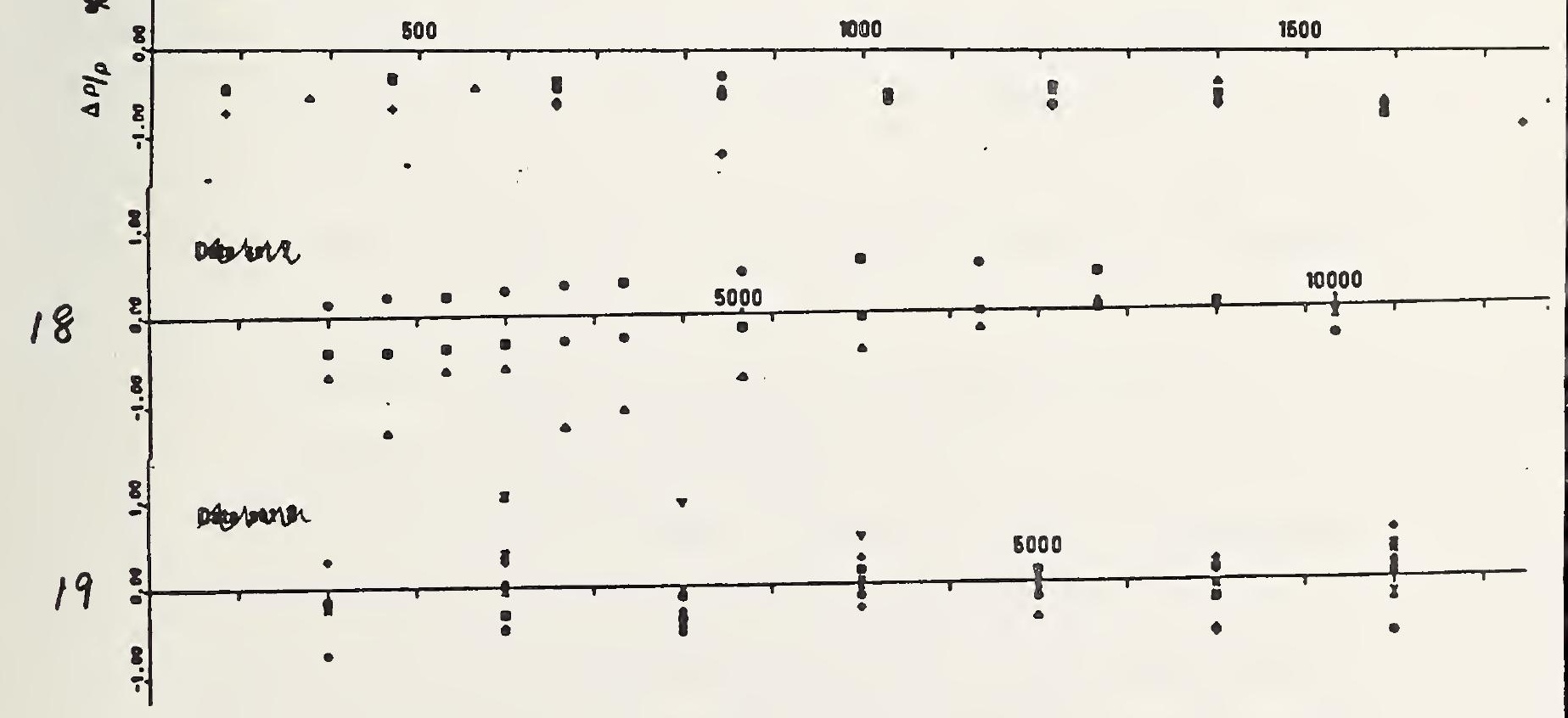



Listing of Fortran program I:

Temperatures, Pressures and Densities along Saturation Curve.

A. The saturation pressure as a function of temperature and the saturation temperature as a function of pressure; where $\mathrm{T}$ is in degrees $K$, and $p$ in atmospheres.

Function PS(T)

Function TS(P)

Function DPSDT(T)

B. The saturation liquid and vapor densities as a function of Temperature: (densities in $\mathrm{gram} / \mathrm{cm}^{3}$ ).

1. SUBROUTINE DS(T,DL, DG) to calculate approximate densities from a simple polynomial to be used as initial guesses for the subroutine DFIND which will improve upon these by an iterative process.

2. SUBROUTINE DFIND(DOUT, P, DGUESS, $T$, DPDD) where $P, T$, DGUESS are inputs, DOUT and DPDD $(\partial P / \partial \rho)$ are outputs and which also uses

3. Function PRES(D,T) which calculates the pressure in atmospheres at any point $\mathrm{D}$ and $\mathrm{T}$

SUBROUTINE QQ(Q,L,K,T,D) which calculates "Q" or the derivatives $\frac{\partial^{L+K} Q}{\partial \rho{ }^{L} \partial \tau} K$ at any point $T$ and $D$.

C. SUBROUTINE HV(HH, T, DL, DG) which calculates the heat of vaporization as a function of $\mathrm{T}$ and the previously calculated liquid and vapor densities. The HV calculated here will be in dimensionless units, and to obtain results in joules per gram multiply by $.4882 \mathrm{~T}$ or in BTU/1b. multiply by .210027 T ( $\mathrm{T}$ in both cases in kelvins). 
D. Units and conversion factors: a package of subroutines is included which will convert Temp. in ${ }^{\circ} \mathrm{F}$ to $\mathrm{K}$ or $\mathrm{K}$ to ${ }^{\circ} \mathrm{F}$, and $\mathrm{P}$ in PSIA to atm. or atm. to PSIA, and densities in $1 \mathrm{~b} / \mathrm{ft}^{3}$ to $\mathrm{gm} / \mathrm{c}^{3}$ or $\mathrm{gm} / \mathrm{c}^{3}$ to $1 \mathrm{~b} / \mathrm{ft}^{3}$. 
F!JNITION PS(T)

$P L=-3684.7798 / T+20.428787+T * 1-.02593284+T *(3.47981 \angle 8 F-5-T * 9.221984$ 15ᄃ -3$) 1$

$P S=F \times P(P L)$

RETURN

FND

FUNCTION TSIP)

$O=1 \cdot / P$

$T=252.1 \cap 703+P *(5.6658636+P * 1-.12457077+P * 1 . \cap 0135987-P * . \cap \cap \cap \cap \cap 5319$

$14211)+Q *(-15.370678+Q *(1.528215-Q * .04906))$

$\cap T \cap P=1 . / \cap P S \cap T(T)$

5. $P X=P S(T)$

TF $(A P S(1 .-P / P X) \cdot L T \cdot 1.5-5)$ r.O TO 10

$D T=(P-P Y) * D T D P$

$T=T+\cap T$

$\operatorname{lin} t=\pi$

in $T S=T$

RETIIRN

FNIT

FUNCT ION DPSDT ( T)

$n F=-.02893289+3684.7798 / T / T+6.95962565-5 * T-2.76659535 F-8 * T * T$

$\cap P S \cap T=\cap F * D S(T)$

RETIJRN

FNO

SUPROUTINF $\cap S(T, \cap L, D R)$

DOURLF PRFCISION T, DL, DG

$D C=.225$

IF $(T-4 \cap 5.4), n, 8 \cap, \cap \cap$

$1 \cap \cap T=? \cdot-T / 4 \cap 5 \cdot 4$

$T=(T \cdot 1 . T \cdot 20 \dot{L} \cdot)$ r. TO TO 100

$T 1=D T * * .25$

$T ?=\cap T * * .547$

$T 2=T$ ? $* T$ ?

$T 4=\cap T * ? .3<52$

$\cap L=T 4+T] *(? .117-1.4 n \cap 7 * T)-$. Qn $0 \cap 2 * T 2)$

$n r=T 4-T 1 *\left(2.117+1.1200 * T>+.57>52 * T^{2}\right)$

$D L=n C *(D L+1 \cdot)$

$n r^{\prime}=n C_{*}\left(n r_{T}+1 \cdot\right)$

RFTIIRN

QD $\cap L=\cap C$

$D C_{-}=D C$

DETIJRN

On $\cap \mathrm{II}=n$.

$n r_{7}=?$.

RFTIIRN

IOn $\cap=\cap T$

$n L=.387131-.00096947 / Q+Q *(1.1513875+Q *(-1.4543106+Q * 1.1183325) 1$

$n r_{7}=.0828867+.00095867 / Q+Q *(-.6 n 039534+(* * 1.4434594$

$1 \quad Q * 1.167960511$

RFTIJRN

EN!ח 
SURROUTTNE DFIND( UUUT,P, T, T, RPR)

COMMON / WOD/ QO, D1, Q2, W 10,20,211

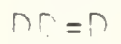

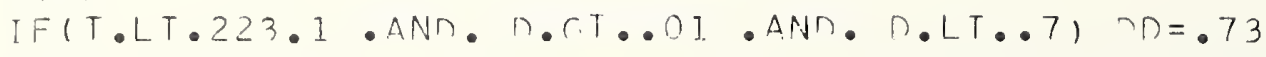

$1=$ ?

$\cap L_{-}=L+1$

$T F(\cap \cap \cdot L F \cdot 0.) \cap \cap n=1 \cdot \Gamma-s$

IF(nn.GT. $\cap), \cap n=.0$

CALL DD(OO,O, O, T, Dก)

CALL QO(Q1, O, 1, T,Dก)

CALL QD(O), ,, ), T, Dก)

$\cap P \cap=\cap P \cap \cap(\cap \cap, T)$

$\cap D \cap X=\cap P \cap$

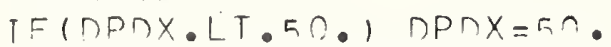

$P P=P R F S(D \cap, T)$

$T F(\wedge P S(1 .-P P / P) \cdot L T \cdot 1 . F-5)$, GO TO ?

$X=(P-P P) / C) P \cap X$

$D D=D \Gamma+x$

IF(L.LF. 2O) GO TO

CONTTNIJE

OOIIT=OO

RFTUIRN

FNIT

FUN! T TON TK(TF)

$T K=(T F+150,57) * 5 . / n$.

RETIIRN

FNI?

FIINTT TON PATM(PSI $\triangle$ )

PATM=PSIA/14.6OK

RFTIIDN

FAI

FUNCTION DREC(DLRCF)

DGCr=ILDCF/G?.4?

RFTIJRN

FND

FUNCTION DLRCF(DGCT)

DLRCF=DOCTER?.42R

RETIIRN!

FNIO

FUNCTION PSTA (PATH)

PST $=$ PATM*14.676

RFTIIRN

FND

FUNCT TON TE (TK)

$T F=] .8 * T K-450.67$

RFTIIRN

FNI 


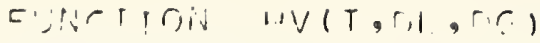

$$
\begin{aligned}
& \text { I) }=\text { ๕9ר. } / \mathrm{T}
\end{aligned}
$$

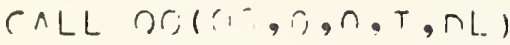

$$
\begin{aligned}
& \text { CALL ?!! }(r, 1, \cap, 1, T, \cap !) \\
& \text { rALL O.) }(r:), 1, \cap, T, r: L)
\end{aligned}
$$

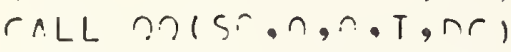

$$
\begin{aligned}
& \text { rALL OO(S, , C, , T, T, R ) } \\
& \text { C } \Delta L L \text { OS(S), I, , T, T, Dr.) }
\end{aligned}
$$

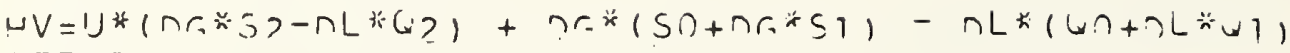

$$
\begin{aligned}
& D E T ! J P A ! \\
& =: 1 n
\end{aligned}
$$

I. 6

A SAMPLE PRORRAH TU TLLCULATE, FUR INSTAIVTE, THE JATIIRATIUIN TFMPFRATIJR IN DEG F, DENSITIES TN LE/CU FT AIVR LFAT UF VAPURTIZLTIUIN TH RTU/LE LT A T.IVEN PRESSIJRE TIN PSTA CUULR DE AS FULLOUS -

$$
D=A, T, D S I
$$

,

$$
\begin{aligned}
& \text { FDRMAT(LEIS.2) } \\
& D=D \triangle T P(P S \text { I) } \\
& T=T \subset(D) \\
& \text { rALL } \cap S\left(T, X \cap L, X \cap r_{9}\right)
\end{aligned}
$$

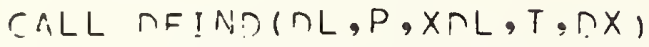

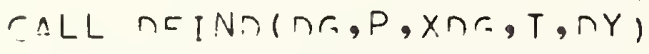

$$
\begin{aligned}
& U \omega=H V(T, \cap L, \cap G) * .>100>7 * T \\
& \Gamma L=\cap L P C F\left(\cap L_{-}\right) \\
& n r=) \text { LRCF(nR) } \\
& T=T F(T) \\
& \text { PRINT !, PSI,TT AL, CR. } 4 \text { H } \\
& S T \cap D \\
& \text { En!n }
\end{aligned}
$$


Listing of Fortran Program II:

Routines for calculating at any point, on the thermodynamic surface.

Subroutine $F Z(T, F, D F, D D F, D T F)$ which calculates for a given temperature

$\mathrm{T}$ in $\operatorname{deg} \mathrm{K}$, the ideal gas functions for the free energy $\mathrm{F}$, entropy $\mathrm{DF}$, $C_{p}$ DDF, and internal energy DTF, all in dimensionless units.

Functions for calculating internal energy, enthalpy, entropy, $\mathrm{C}_{\mathrm{p}}$ and $\mathrm{C}_{\mathrm{v}}$ as functions of $\mathrm{D}, \mathrm{T}$ and ideal gas functions, all in dimensionless units.

Phase finder: SUBRoUTINE PHASE ( $P, T, D L, D G, K)$ which will, for any point $\mathrm{P}$ and $\mathrm{T}$ supplied, return a value of $\mathrm{K}$ as follows:

$\mathrm{K}=0$ point is on sat. curve. guesses for DL and DG returned $K=1 \mathrm{~T}<\mathrm{T}_{C}$, vapor phase. guess for $\mathrm{DG}$ returned, $\mathrm{DL}$ set $=\mathrm{DG}$ $\mathrm{K}=2 \mathrm{~T}<\mathrm{T}_{C}$, liquid phase. guess for $\mathrm{DL}$ returned, $\mathrm{DG}$ set $=\mathrm{DL}$ $\mathrm{K}=3 \mathrm{~T}>\mathrm{T}_{\mathrm{C}} \mathrm{DG}=\mathrm{DL}$, guess returned.

$\mathrm{K}=-1$ error return for $\mathrm{T} \leq$ or $\mathrm{P} \leq 0$. or for either $\mathrm{P}$ missing and $\mathrm{T}>\mathrm{T}_{\mathrm{C}}$ for $\mathrm{T}<\mathrm{T}_{\mathrm{c}}$, and $\mathrm{P}$ missing or $=0 ., \mathrm{P}_{\text {sat }}$ will be calculated, and the appropriate densities found. Similarly, for $\mathrm{P}<\mathrm{P}_{c}$ and $\mathrm{T}$ missing or $=0$. , T $_{\text {sat }}$ will be calculated. 
SURROUTTNF FZ(T, F, IF, DAF, DTT)

DOURLF PRFCTSION T

CI MFNSTON A (1)

DATA $1 /-3.872727, .64463724, . \angle 238759,-.0 n 21376925, .06890833 F-5$.

$1-.24085149 F-7, .36893175 F-10,-.33924664 F-13, .20563027 \mathrm{~F}-16$,

$2-.685 .34 \mathrm{~F}-20, .97392427 F-24,0.1$

$U=T$

IF(T.LF.10. U U $=10$.

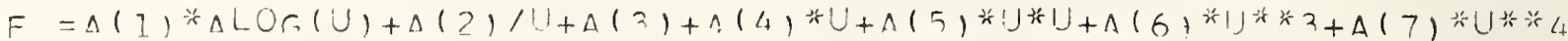

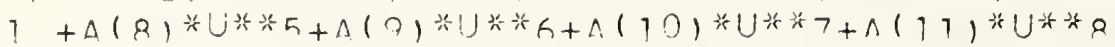

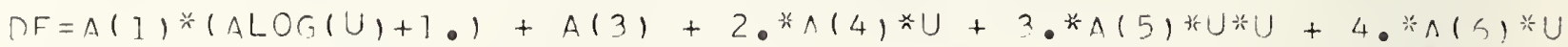

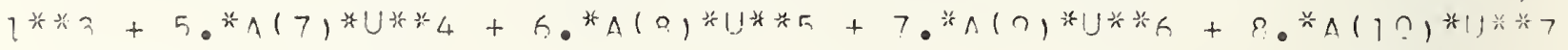

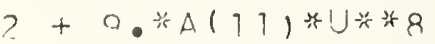

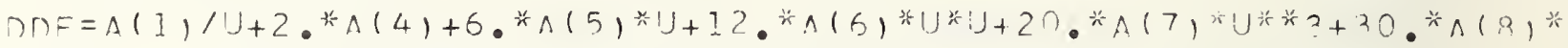

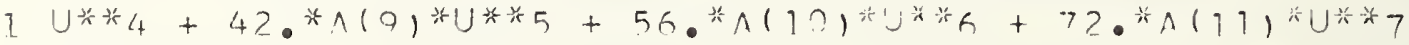

$D D F=-D D F * U$

$D F=-D F$

$D T F=\cap F+F-1$.

RFTIIRN

END

SUBROUTINF PHASF(P,T, DL, DG, N)

IF (P) $10,10,20$

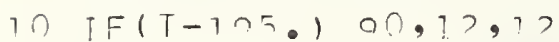

1) TF(T-4)

$14 P=P S(T)$

if CALL חS(T,DL, n

$K=$ ?

RFTURN

20 IF (T) ?.2, ??, 30

22 IF $(P-111.55) ? 4,74,00$

24 IF (P-.06) $\cap 0,26,26$

$26 T=T S(P)$

GO TO ?

30 $T F(T-425.5) \quad 27,50,50$

3) $P X=P S(T)$

3.4 CALL DS(T, NL,DG)

IF $(P-P X) 3,6,14,4 C$

36 $D G=D G * P / P X$

$D L=D G_{7}$

$K=$ ?

RFTURN

4? $D G=\cap L$

$k=$ ?

RETURN

$50 D=P * 1.0002107-5.13 F-8 * P-2.289 F-7 * T 1-1.2823 F-6 * T$

$D=D+P / T / 4 \cdot 818$

$I F(D \cdot L T \cdot T \cdot F-5) \cap=. \cap \cap \cap \cap 1$

$\Gamma L=D$

$D G=D L$

$K=3$

RETURN

an $D L=n$.

$D G=0$.

$K=-1$

RFTURN

FND 
II. 3

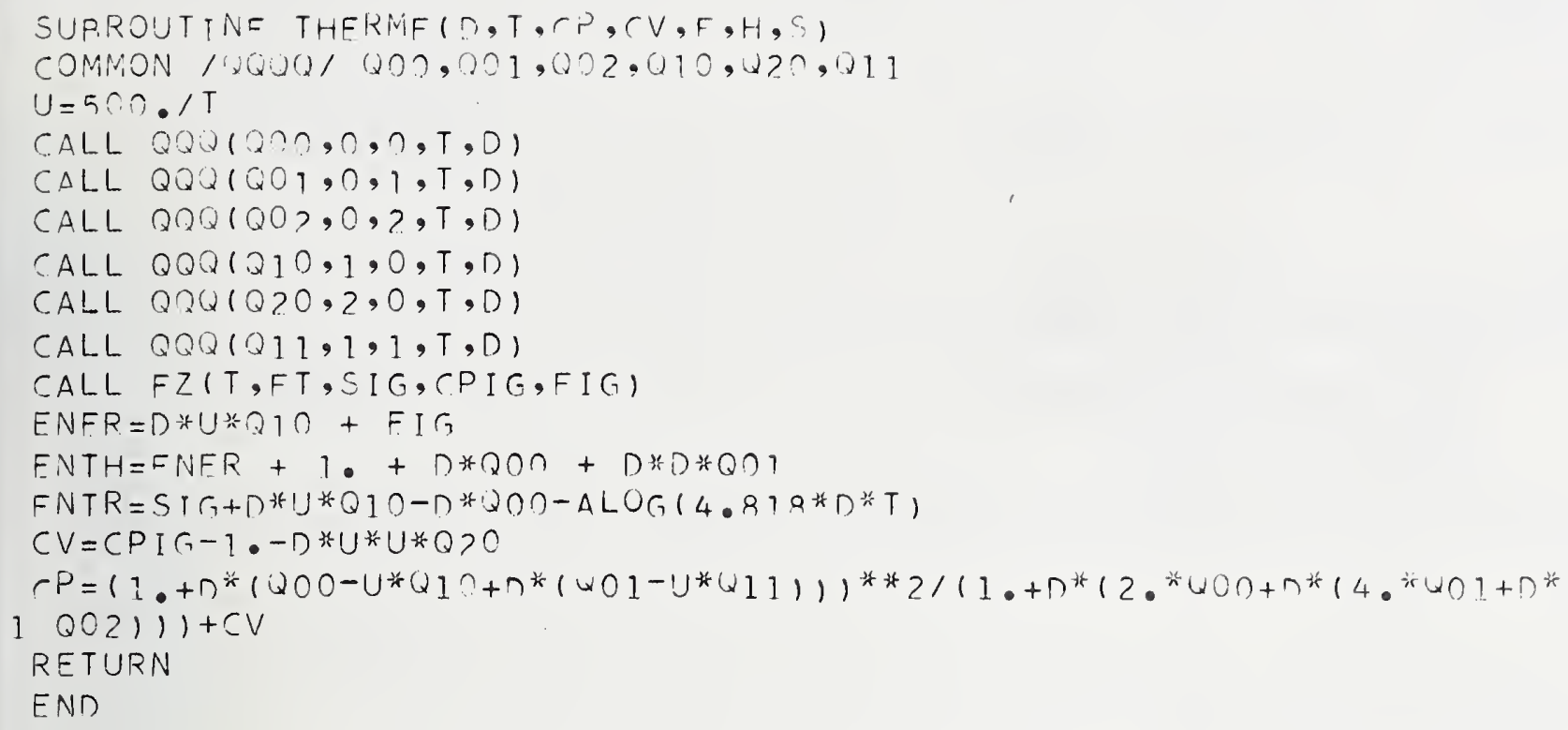

THF FOLLONTNG SAMPLF PROGRAM WILL CALCULATF THF DENSITY AND FIVF THFRMODYNAMIC FUNCTIUNS AT A POINT (P,T) SUPPLIED. P SUPPLIED IN RAR, T IN DFG C DFNSITY IN GM/CC, CP, CV,S IN JUULFS/GM OFR C, AND INTERNAL FNFRGY, EINTHALPY IN JOULFS/GM.

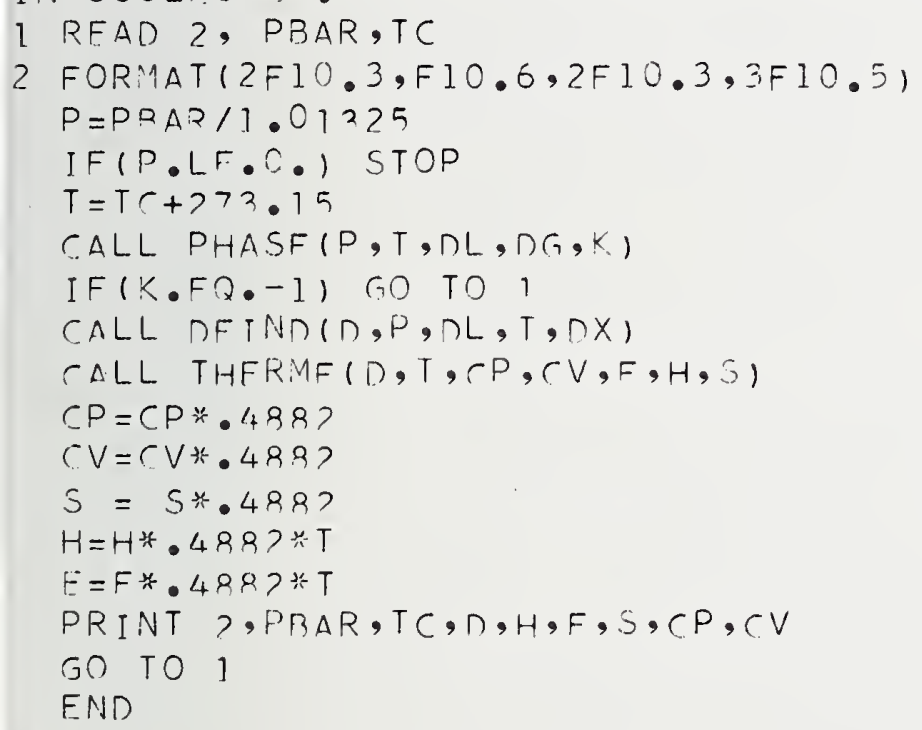


NBS-114A IREV.7-73)

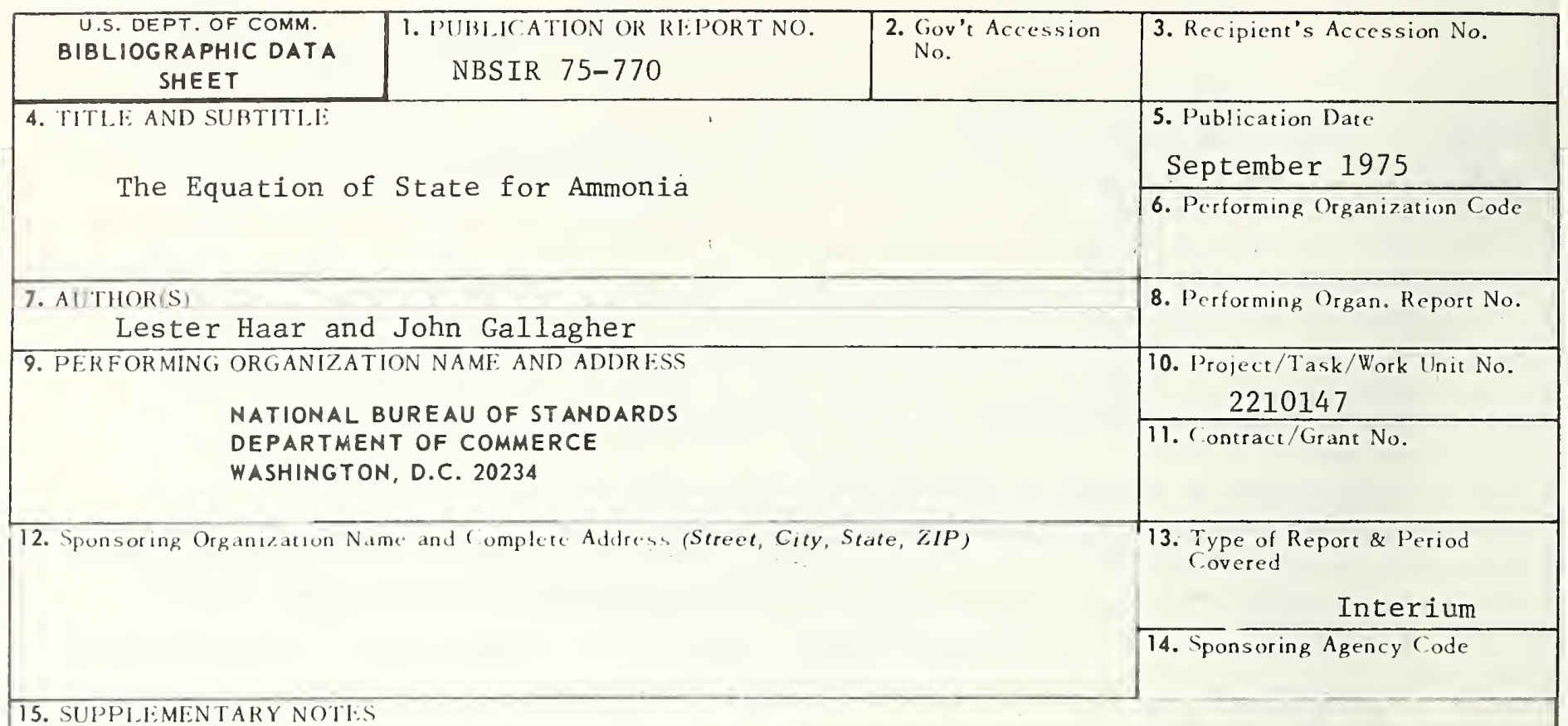

16. ABSTRAC:T (A 200-word or less factual summary of most significant information. If document includes a significant bibliography or literature survey, mention it here.)

An outline is presented of the basic results of the extensive correlation for the thermodynamic properties of ammonia recently completed at this laboratory. Computer programs are presented for the calculation of thermodynamic properties in the range including the triple point temperature to $5 / 3$ the critical temperature and pressures from the dilute gas to 8000 bar.

17. KEY WORDS (six to twelve entries, alphabetical order, capitalize only the first letter of the first key word unless a proper name; separated by semicolons) Ammonia; correlation; gas; 1iquid; thermodynamic properties; thermodynamic surface.

18. AVAILABILITY

[X] Unlimited

For Official Distribution. Do Not Release to N7 IS

Order From Sup. of Doc., U.S. Government Printing Office

Washington, D.C. 20402, SDCat. No. C 13

Order from National Technical Information Service (NTIS) Springfield, Virginia 22151

\begin{tabular}{|c|c|}
\hline $\begin{array}{l}\text { 19. SECURITY CLASS } \\
\text { (THIS REPORT) } \\
\text { UNCL ASSIFIEI) }\end{array}$ & 21. NO. OF PAGES \\
\hline $\begin{array}{l}\text { 20. SECURITY CIAASS } \\
\text { (TIIS PACE) }\end{array}$ & 22. Price \\
\hline UNCLASSIIILD & $\$ 3.75$ \\
\hline
\end{tabular}


